\title{
PESQUISA EM EMPREENDEDORISMO NO PRINCIPAL PERIÓDICO INTERNACIONAL: UM ESTUDO BIBLIOMÉTRICO DAS PUBLICAÇÕES NO JOURNAL OF BUSINESS VENTURING ENTRE 1987 E 2010
}

\author{
Manuel Portugal Ferreira - UNINOVE e Instituto Politécnico de Leiria ${ }^{1}$ \\ Rui Miranda - Instituto Politécnico de Leiria² \\ Nuno Rosa dos Reis - Instituto Politécnico de Leiria ${ }^{3}$ \\ Cláudia Frias Pinto - UNINOVE \\ Fernando Ribeiro Serra - UNINOVE
}

\begin{abstract}
Resumo: Este artigo visa entender o estoque de conhecimento acumulado na pesquisa em empreendedorismo. Um estudo bibliométrico dos artigos publicados entre 1987 e 2010 no Journal of Business Venturing. As análises, sobre uma amostra de 413 artigos, incide nos autores mais prolíficos, nacionalidade, frequência de citações, redes de cocitações e dos temas pesquisados no período. Observa-se que a pesquisa tem sido liderada por norte-americanos e confirma-se a multidisciplinaridade da pesquisa em empreendedorismo que em absorvido da maioria das teorias de Administração, da teoria da agência aos custos de transação, e da visão baseada nos recursos ao ambiente social em que os empreendedores e a criação de novas empresas estão imersos. No entanto, notamos que embora o campo de empreendedorismo seja vasto, a pesquisa se concentra mais em torno de temas como os recursos para o empreendedorismo, criação de valor e desempenho, ambiente externo e determinantes do empreendedorismo, 0 processo empreendedor, características psicológicas e individuais do empreendedor e aspetos metodológicos.
\end{abstract}

Palavras-chave: estudo bibliométrico, Journal of Business Venturing, citações, cocitações, temas de pesquisa em empreendedorismo

\section{Extant entrepreneurship research in its premier international journal: A BIBLIOMETRIC STUDY OF THE PUBLICATIONS IN THE JOURNAL OF BUSINESS VENTURING BETWEEN 1987 AND 2010}

\begin{abstract}
This paper seeks to make sense of the stock of knowledge on entrepreneurship research. A bibliometric study of the articles published between 1987 and 2010 in the Journal of Business Venturing. The analyses, on a sample of 413 articles focuses on the most productive authors, geography, citations frequency,

\footnotetext{
${ }^{1}$ E.mail:Manuel.portugal.ferreira@gmail.com - Endereços: Av. Francisco Matarazzo, 612, prédio C $1^{\circ}$ andar. CEP: 05001-100, São Paulo, Brasil. Morro do Lena - Alto do Vieiro CEP:2411-901 Leiria, Portugal.

2 E.mail: rmiranda@portugalmail.pt

${ }^{3}$ E.mail: nuno.m.r.reis@gmail.com

${ }^{4}$ E.mail: claudia.frias.pinto@gmail.com

${ }^{5}$ E.mail: fernandoars@uninove.br
}

FERREIRA, M. P.; MIRANDA, R.; REIS, N. R.; PINTO, C. F.; SERRA, F. R. Pesquisa em empreendedorismo no principal periódico internacional: um estudo bibliométrico das publicações no journal of business venturing entre 1987 e 2010. Revista de

Empreendedorismo e Gestão de Pequenas Empresas, v. 3, n.1, p. 56-83, 2014. 
co-citation networks and the researched themes delved upon over the period. We found that research has been largely driven by North-American English-speaking scholars and confirmed the multidisciplinarity of entrepreneurship research that has absorbed from the majority of management theories, from agency to transaction costs, and from the resource based view to the social milieu in which entrepreneurs and new firms founding are embedded. However, we also found that albeit the field of study of entrepreneurship is vast, it seems to concentrate on issues related to entrepreneurial resources, entrepreneurial process, value creation and performance, environmental and external determinants of entrepreneurship, psychological, cognitive and individual characteristics and methodological issues.

Keywords: bibliometric study, Journal of Business Venturing, citations, co-citations, research themes, entrepreneurship research

\section{INTRODUÇÃO}

Estudos envolvendo a análise retrospectiva do conhecimento acumulado numa disciplina ou campo de estudo são frequentes com o maturar da própria disciplina. Estes estudos têm o benefício potencial de não apenas fazer uma análise crítica e súmula do estoque de conhecimento existente mas, também, apontar novas direções e novos desafios (LOW; MACMILLAN, 1988). A pesquisa em empreendedorismo não é recente mas parece ter ganho ainda maior ímpeto com a crise econômica e social em diversos países ocidentais, talvez mais especialmente na Europa e EUA, face à incapacidade de os estados terem soluções e os indivíduos sendo chamados a assumir responsabilidades. Efetivamente, o desenvolvimento institucional da disciplina revela-se na grade de cursos das universidades, nos centros e agências de fomento dedicadas ao empreendedorismo, na criação de soluções como as incubadoras e parques tecnológicos, e mesmo no surgimento de periódicos especializados para a publicação de pesquisa em empreendedorismo. Assim, encontramos periódicos como o Journal of Business Venturing, Entrepreneurship Theory and Practice, Strategic Entrepreneurship Journal, Small Business Economics, Entrepreneurship and Regional Development, International Small Business Journal, Journal of Small Business Management, entre outros.

Embora os progressos institucionais em empreendedorismo (ALDRICH, 2012), numa ótica de pesquisa e numa ótica de política pública, sejam substanciais, alguns acadêmicos argumentam que a pesquisa em empreendedorismo ainda está na sua

FERREIRA, M. P.; MIRANDA, R.; REIS, N. R.; PINTO, C. F.; SERRA, F. R. Pesquisa em empreendedorismo no principal periódico internacional: um estudo bibliométrico das publicações no journal of business venturing entre 1987 e 2010. Revista de

Empreendedorismo e Gestão de Pequenas Empresas, v. 3, n.1, p. 56-83, 2014. 
infância (SHANE; VENKATARAMAN, 2000; LOW, 2001; NICHOLLS 2010) e outros questionam mesmo qual o seu domínio, face à ausência de teorias específicas e à multiplicidade de fenômenos e contextos analisados. No entanto, esclarecemos que o objetivo deste artigo não é fazer uma revisão da literatura ou um estudo exaustivo de todas as teorias, métodos e contextos em que se tem desenvolvido a pesquisa em empreendedorismo. Revisões de literatura, seguindo diferentes métodos, focos e períodos podem ser consultadas em trabalhos como Low e MacMillan (1988), Busenitz et al. (2003), Cooper (2003), Teixeira (2011), entre vários outros trabalhos recentes. O objetivo também não é questionar a legitimidade de uma disciplina em empreendedorismo ou definir qual o seu domínio (DAVIDSSON, 2003; CORNELIUS et al., 2006; ALDRICH, 2012).

A área de pesquisa em empreendedorismo tem aproximadamente 30 a 40 anos e tem crescido para hoje ser uma disciplina com atividade intelectual munificente envolvendo milhares de acadêmicos em todo o mundo. Neste artigo, visamos entender o estoque acumulado de conhecimento na pesquisa internacional em empreendedorismo, focando evolução da pesquisa, autores mais produtivos, trabalhos mais citados, estrutura intelectual e temas pesquisados. Por meio de um estudo bibliométrico dos artigos publicados no principal periódico internacional de empreendedorismo (RATNATUNGA; ROMANO, 1997; HARZING, 2011) - o Journal of Business Venturing -, num período de 24 anos, entre 1987 e 2010, efetuamos análises de citações, redes de cocitações e dos temas pesquisados, numa amostra de 413 artigos. O estudo bibliométrico permite uma análise objetiva que sustenta entender melhor a estrutura intelectual que liga autores, temas e teorias (WHITE; MCCAIN, 1998; RAMOS-RODRIGUEZ; RUIZ-NAVARRO, 2004), sendo uma base a partir da qual antevemos se consiga desenhar uma agenda de pesquisa útil para os pesquisadores brasileiros.

Os resultados mostram uma tendência ascendente na pesquisa em empreendedorismo, ainda que com origem primordial em autores e instituições norte-americanas. A análise da estrutura intelectual revela prima facie a grande diversidade que tem caracterizado a pesquisa, que inclui abordagens conceituais das principais teorias de Administração como a visão baseada em recursos, teoria 
dos custos de transação, redes sociais e aprendizagem organizacional. Salienta-se, ainda, a preocupação com questões metodológicas e a discussão sobre o domínio e existência com um corpus próprio da disciplina, que tem alimentado um debate extenso. Também fica evidente a forte diversidade temática da pesquisa. No entanto, denota-se já alguma especificidade que sinaliza um corpo conceitual ou objeto próprio, talvez suportando a ideia exposta em Teixeira (2011) dos colégios (in)visíveis.

Este artigo está estruturado em três partes. Primeiro, a metodologia inclui uma descrição do método bibliométrico e seu uso na pesquisa, seguida pelos procedimentos de coleta da amostra e procedimentos de análise usados. A segunda parte, mostra os resultados. A terceira parte contempla uma discussão mais alargada com a indicação de limitações e vias para pesquisas futuras.

\section{MÉTODO}

Neste artigo realizamos um estudo bibliométrico dos artigos publicados no principal periódico de empreendedorismo (ver Tabela 1 para um ranking). As análises bibliométricas são, frequentemente, realizadas na pesquisa para aferir tendências (WHITE; MCCAIN, 1998), conexões entre autores e teorias (DIODATO, 1994), temas investigados (SCHILDT; ZAHRA; SILLANPÄÄ, 2006), os autores que mais publicam ou mais produtivos (SHANE, 2000; CORNELIUS; LANDSTRÖM; PERSSON, 2006), o impacto de um autor, trabalho ou instituição (SHANE, 1997), a estrutura intelectual de um campo de estudos ou disciplina (RAMOS-RODRIGUEZ; RUIZ-NAVARRO, 2004; SHAFIQUE, 2013) e quais os artigos que são mais citados (RATNATUNGA; ROMANO, 1997).

Neste artigo focamos os artigos publicados em um periódico especifico Journal of Business Venturing (JBV) - ao longo de um período de tempo alargado de 24 anos, entre 1987 e 2010 (que é o período em que os artigos estão disponíveis na base de dados ISI web of knowledge, comercializada pela Thomson). Seguimos 0 método e procedimentos propostos em Ramos-Rodriguez e Ruiz-Navarro (2004), complementando com os procedimentos em Ratnatunga e Romano (1997) para a 
análise de citações. Assim, este artigo complementa outros estudos de revisão da literatura e de avaliação do estado da arte na disciplina. Por exemplo, o trabalho de Shane (1997) que estudou o impacto de autores e instituições na Pesquisa em empreendedorismo. Busenitz et al. (2003) avaliou o potencial da área de empreendedorismo e o seu progresso acadêmico. Cornelius, Landström e Persson (2006) examinaram os principais autores que são citados para buscar entender se o conhecimento acumulado em empreendedorismo tem origem no desenvolvimento próprio do tema ou em imitação da pesquisa de outras disciplinas. Gartner, Davidsson e Zahra (2006) mostram que as técnicas bibliométricas servem bem para entender as ligações entre autores que pesquisam empreendedorismo. Grégoire et al. (2006) verificaram se havia convergência na Pesquisa em empreendedorismo. Keupp e Gassmann (2009) analisaram a pesquisa em empreendedorismo internacional e suas conexões com outras disciplinas como estratégia, negócios internacionais e gestão da inovação. Kraus (2011) realizaram uma revisão da literatura em empreendedorismo internacional e Shane e Venkataraman (2000) visaram identificar uma definição de empreendedorismo.

\section{Procedimentos e amostra}

Os procedimentos de definição e coleta da amostra para a análise empírica envolveu três grandes etapas. Primeiro, a definição do escopo, que delimitamos a apenas o premier periódico internacional em empreendedorismo - Journal of Business Venturing (JBV). O JBV tem um fator de impacto a 5 anos de 3,954, no journal citation report, e é comparando positivamente com outros periódicos em diferentes rankings disponibilizados no journal quality list 2013 (Harzing, 2013) em www.harzing.com/jgl.htm. Segundo, a delimitação do horizonte temporal suficientemente alargado de modo a conseguir captar adequadamente o estoque de conhecimento existente. Definimos um período de 24 anos, entre 1987 a 2010, os anos em que os artigos publicados no periódico estão disponíveis na base de dados ISI Web of knowledge, da Thomson Reuters. Como nos interessa o estoque de conhecimento não são realizadas análises longitudinais. A terceira etapa envolveu

FERREIRA, M. P.; MIRANDA, R.; REIS, N. R.; PINTO, C. F.; SERRA, F. R. Pesquisa em empreendedorismo no principal periódico internacional: um estudo bibliométrico das publicações no journal of business venturing entre 1987 e 2010. Revista de

Empreendedorismo e Gestão de Pequenas Empresas, v. 3, n.1, p. 56-83, 2014. 


\section{REG Apt A Revista da ANEGEPE

definir os termos de pesquisa. Para a seleção de uma amostra representativa que espelhasse o estado da arte da pesquisa publicada sob o tema genérico de empreendedorismo, não incluímos simplesmente todos os artigos publicados no JBV. Antes, efetuámos uma busca utilizando a sugestão de Busenitz et al. (2003) que identificaram seis palavras chave específicas melhor ajustadas para buscar trabalhos de empreendedorismo: entrepreneur, entrepreneurial, entrepreneurship, small business, new ventures e founders. Estas palavras-chave foram inseridas no campo "topic" no motor de busca da Web of Knowledge mas de forma a garantir que os artigos não seriam duplicados na amostra. Para garantir, a amostra final foi confirmada para eliminar eventuais repetições.

Tabela 1. Classificação (ranking) dos periódicos em empreendedorismo

\begin{tabular}{|l|c|c|c|c|c|c|c|c|}
\hline \multicolumn{1}{|c|}{ Periódico } & $\begin{array}{c}\text { Ano de } \\
\text { fundação }\end{array}$ & $\begin{array}{c}\text { Aeres } \\
\mathbf{2 0 1 2}\end{array}$ & $\mathbf{2 0 0 8}$ & $\mathbf{2 0 1 1}$ & $\mathbf{2 0 1 0}$ & $\mathbf{2 0 1 2}$ & $\begin{array}{c}\text { Fator } \\
\text { de } \\
\text { impacto } \\
-\mathbf{5} \text { anos }\end{array}$ & $\begin{array}{c}\text { Total } \\
\text { citações }\end{array}$ \\
\hline $\begin{array}{l}\text { Journal of } \\
\text { Business } \\
\text { Venturing }\end{array}$ & 1986 & $\mathrm{~A}$ & 3 & 1 & $\mathrm{~A}^{*}$ & 3 & $\mathbf{3 , 9 5 4}$ & 3.674 \\
\hline $\begin{array}{l}\text { Entrepreneurship } \\
\text { Theory and } \\
\text { Practice }\end{array}$ & 2002 & $\mathrm{~A}$ & 3 & 1 & $\mathrm{~A}^{*}$ & 3 & $\mathbf{3 , 4 5 1}$ & 2.830 \\
\hline $\begin{array}{l}\text { Journal of } \\
\text { Product } \\
\text { Innovation } \\
\text { Management }\end{array}$ & 1984 & $\mathrm{~A}$ & 4 & 1 & $\mathrm{~A}$ & 4 & $\mathbf{3 , 1 1 1}$ & 3.157 \\
\hline $\begin{array}{l}\text { Strategic } \\
\text { Entrepreneurship } \\
\text { Journal }\end{array}$ & 2007 & $\mathrm{~A}$ & - & 2 & $\mathrm{C}$ & - & $\mathbf{3 , 1 0 5}$ & 335 \\
\hline $\begin{array}{l}\text { Small Business } \\
\text { Economics }\end{array}$ & 1989 & $\mathrm{~A}$ & 2 & 2 & $\mathrm{~A}$ & 3 & $\mathbf{2 , 2 2 8}$ & 1.997 \\
\hline $\begin{array}{l}\text { International } \\
\text { Small Business } \\
\text { Journal }\end{array}$ & 1982 & $\mathrm{~A}$ & - & 2 & $\mathrm{~B}$ & 2 & $\mathbf{2 , 1 1 9}$ & 727 \\
\hline $\begin{array}{l}\text { Entrepreneurship } \\
\text { \& Regional } \\
\text { Development }\end{array}$ & 1989 & $\mathrm{~B}$ & 2 & 3 & $\mathrm{~B}$ & 2 & $\mathbf{1 , 9 5 1}$ & 823 \\
\hline
\end{tabular}

FERREIRA, M. P.; MIRANDA, R.; REIS, N. R.; PINTO, C. F.; SERRA, F. R. Pesquisa em empreendedorismo no principal periódico internacional: um estudo bibliométrico das publicações no journal of business venturing entre 1987 e 2010. Revista de

Empreendedorismo e Gestão de Pequenas Empresas, v. 3, n.1, p. 56-83, 2014. 
Journal of Small

Business

2001

A

2

2

A

1

1,333

1.194

Management

Notas: AERES 2012 - Agence d'évaluation de la recherche et de l'enseignement supérieur, October 2012 (A High/C Low); AST 2008 - Aston Business School, March 2008 (4 High / 0 Low); CNRS 2011 - Centre National de la Recherche Scientifique, October 2011 (version 3.01) ( $1^{*}$ High/4 Low); ABDC 2010 - Australian Business Deans Council Journal Rankings List February 2010 ( A $^{*}$ High/C Low); CRA 2012 - Cranfield University School of Management February 2012 (4 High/1 Low).

Fonte: Journal Quality List $2013,50^{\text {th }}$ edition. Os dados de citações e do fator de impacto a 5 anos foram coletados do Journal Citation Report - Social Science Edition 2012.

Os procedimentos retornaram uma amostra final de 413 artigos dos 781 documentos publicados no JBV no período de 1987 a 2010. De salientar que filtrámos por artigos apenas, não incluindo notas editorais, revisões de livros (book reviews), e outros documentos, dado que os artigos avaliados por referees são comumente referidos como conhecimento certificado num processo de avaliação pelos pares (ver RAMOS-RODRIGUEZ; RUÍZ-NAVARRO, 2004). Os 413 artigos da amostra, publicados desde 1987, foram escritos por 615 autores e utilizaram 13.721 referências diferentes.

\section{Procedimentos de análise}

Análise de citações. A análise de citações é, em essência, a contagem de quantas vezes um trabalho é utilizado por outros e o seu valor é baseado na assunção que um maior número de citações é uma medida de impacto (WHITE; MCCAIN, 1998) porque são mais vezes utilizados por outros autores (ACEDO et al., 2006). Efetivamente, métricas de citações são utilizadas para avaliar a contribuição de acadêmicos e muitas universidades, talvez mais especialmente nos Estados Unidos, usam-nas nas decisões de promoção e tenure. Mas, na prática do trabalho científico os autores citam outras obras que lhes são relevantes quer para comparar resultados, para fundamentar o uso de dada metodologia ou forma de mensuração, para posicionar num corpo teórico e para utilizar uma teoria ou ideia.

Análise de cocitações. Visa identificar pares de artigos que são mais frequentemente citados em conjunto; ou seja, que são cocitados por um terceiro

FERREIRA, M. P.; MIRANDA, R.; REIS, N. R.; PINTO, C. F.; SERRA, F. R. Pesquisa em empreendedorismo no principal periódico internacional: um estudo bibliométrico das publicações no journal of business venturing entre 1987 e 2010. Revista de

Empreendedorismo e Gestão de Pequenas Empresas, v. 3, n.1, p. 56-83, 2014. 
artigo. A assunção subjacente é que as cocitações permitem identificar relações conceituais, ou de proximidade, entre os artigos a sua relevância para o autor do artigo que as cita (WHITE; GRIFFITH, 1981; WHITE; MCCAIN, 1998; RAMOSRODRIGUEZ; RUIZ-NAVARRO, 2004). Assim, um maior número de cocitações pode ser usado como indicador de relevância do trabalho para um determinado tema ou disciplina (RAMOS-RODRIGUEZ; RUIZ-NAVARRO, 2004). Por exemplo, Small e Griffith (1974) usaram esta técnica para mapear áreas de pesquisa. Déry e Toulouse (1996) usaram análises de cocitações para estabelecer e confirmar a estrutura social na Pesquisa em empreendedorismo. White e McCain (1998) notaram que análises de citações e cocitações de artigos permitem entender a evolução e tendências de uma disciplina e a contribuição de uma obra para a pesquisa existente (ver FERREIRA, 2011).

Análise dos temas pesquisados. Para identificar os temas pesquisados, e construir uma rede de relações entre os temas, seguimos a proposta de Furrer, Thomas e Goussevskaia (2008) de usar as palavras-chave fornecidas pelos autores para inferir o conteúdo dos artigos, agrupando-as em temas mais amplos. Primeiro, com o software Bibexcel extraímos de cada artigo as palavras-chave fornecidas pelos autores. Utilizar as palavras-chave para inferir temas é adequado porquanto os autores escolhem as palavras-chave que melhor sinalizam a potenciais leitores 0 conteúdo dos artigos, além de para efeitos de indexação nas bases bibliográficas. Apenas 190 artigos continham as palavras chave disponíveis na ISI web of knowledge, resultando em 760 palavras-chave diferentes. Em seguida, identificámos os principais temas de pesquisa em empreendedorismo, para o que seguimos os 24 temas identificados no trabalho de Schildt, Zahra e Sillanpää (2006). Dois assistentes de pesquisa fizeram a classificação das palavras pelos temas de forma independente e, depois, conjuntamente, verificaram eventuais discordâncias, resolvendo-as com o pesquisador principal. Como os artigos contém, usualmente, entre três e cinco palavras-chave, significa que cada artigo pode ser classificado em mais do que um tema. Esta consequência parece ajustada porque efetivamente um artigo pode, por exemplo, fazer uso de uma teoria, focar um contexto em específico 
e utilizar algum tipo de metodologia. Os temas e as palavras-chave estão inclusos em anexo.

\section{RESULTADOS}

Os resultados das análises permitem fazer observações descritivas da evolução anual das publicações, da distribuição geográfica (ou nacionalidade) das autorias, dos autores mais produtivos, dos trabalhos mais citados, das relações, ou redes, de cocitações e dos temas pesquisados. Mostramos as análises em seguida.

A análise do histórico de publicações mostra uma tendência ascendente (Figura 1) nos artigos publicados, seguindo os parâmetros definidos. Verificamos um pico atingido em 2010, com 33 artigos, mas há oscilações anuais substanciais, com picos secundários em 1993 e 1997 em contraste com depressões em 1996 e 1999. As flutuações anuais poderiam ser consequência de mudanças na política editorial ou de edições relacionadas a fatores exógenos. Mas, não identificamos variações na política editorial do JBV ou o lançamento de números especiais que expliquem estas variações.

\section{Figura 1. Evolução das publicações}

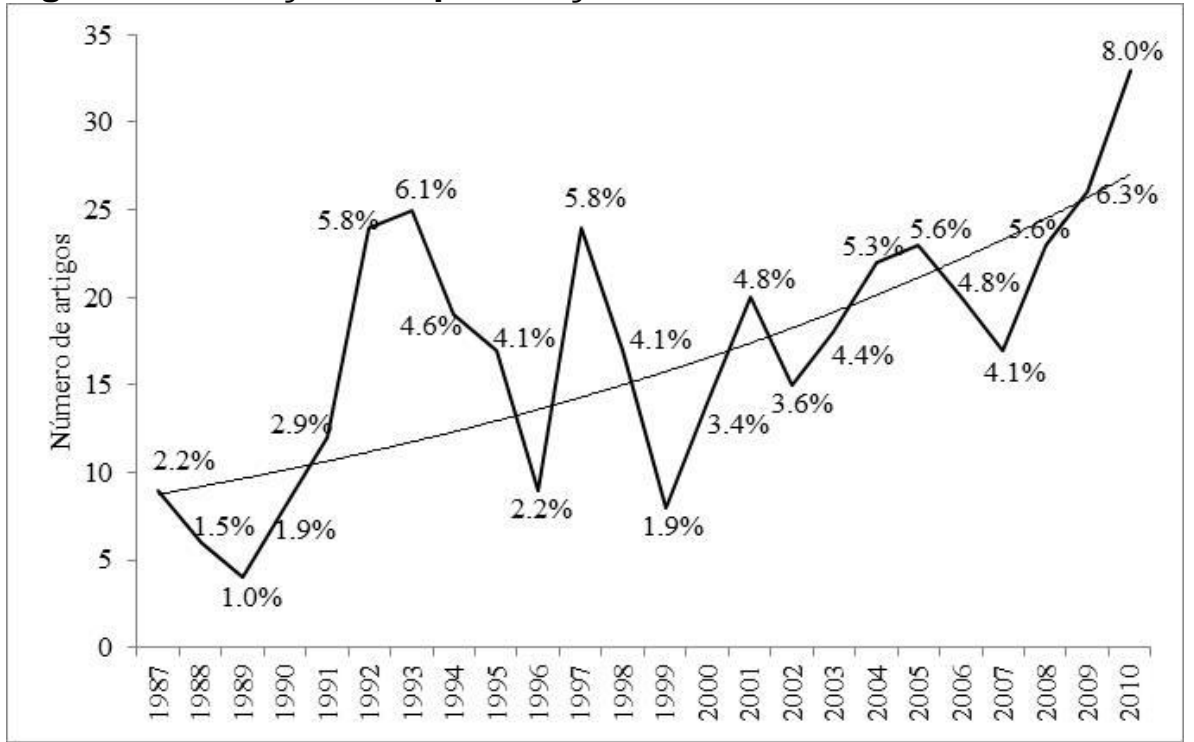

Nota: Total de 413 artigos.

Fonte: dados coletados de ISI Web of Knowledge. Cálculos dos autores.

FERREIRA, M. P.; MIRANDA, R.; REIS, N. R.; PINTO, C. F.; SERRA, F. R. Pesquisa em empreendedorismo no principal periódico internacional: um estudo bibliométrico das publicações no journal of business venturing entre 1987 e 2010. Revista de

Empreendedorismo e Gestão de Pequenas Empresas, v. 3, n.1, p. 56-83, 2014. 


\section{Geografia e autores mais citados}

Para observar a origem das pesquisas organizámos os dados da amostra de modo a classificar a nacionalidade reportada pelos autores. Esta análise é feita com todas as afiliações de todos os autores, pelo que o número de nacionalidades (630) é ligeiramente superior ao número de autores (615), dado que alguns autores reportam mais que uma instituição. A Tabela 2 resume os dados mostrando largo predomínio dos Estados Unidos (389 artigos), seguidos pelo Canadá (49) e Inglaterra (36). Ou seja, apenas três países - EUA, Canadá e Inglaterra respondem por $75 \%$ dos artigos publicados. É impactante notar que mais de metade $(61,5 \%)$ das afiliações se referem a universidades norte-americanas e seria relevante compreender se esta evidência é indicativa da maior ênfase dada à pesquisa em empreendedorismo nos EUA face a outros países, ou até que ponto as dificuldades de publicar em inglês poderá estar a contribuir para o menor numero de publicações por não nativos da língua inglesa.

Tabela 2. Distribuição geográfica dos autores

\begin{tabular}{|c|c|c|c|c|c|}
\hline País & $\begin{array}{c}\text { № } \\
\text { artigos }\end{array}$ & $\%$ & País & $\begin{array}{c}\text { № } \\
\text { artigos }\end{array}$ & $\%$ \\
\hline $\begin{array}{l}\text { Estados } \\
\text { Unidos }\end{array}$ & 389 & 61,55 & Suíça & 5 & 0,79 \\
\hline Canadá & 49 & 7,75 & Noruega & 3 & 0,47 \\
\hline Inglaterra & 36 & 5,70 & Coreia do Sul & 3 & 0,47 \\
\hline Alemanha & 17 & 2,69 & Dinamarca & 2 & 0,32 \\
\hline Suécia & 15 & 2,37 & Rússia & 2 & 0,32 \\
\hline Holanda & 14 & 2,22 & Eslovénia & 2 & 0,32 \\
\hline Itália & 12 & 1,90 & Vietnã & 2 & 0,32 \\
\hline Singapura & 12 & 1,90 & Finlândia & 1 & 0,16 \\
\hline Austrália & 11 & 1,74 & Gana & 1 & 0,16 \\
\hline
\end{tabular}

FERREIRA, M. P.; MIRANDA, R.; REIS, N. R.; PINTO, C. F.; SERRA, F. R. Pesquisa em empreendedorismo no principal periódico internacional: um estudo bibliométrico das publicações no journal of business venturing entre 1987 e 2010. Revista de

Empreendedorismo e Gestão de Pequenas Empresas, v. 3, n.1, p. 56-83, 2014. 


\section{REG A A Revista da ANEGEPE

\begin{tabular}{|l|c|c|}
\hline Israel & 11 & 1,74 \\
\hline China & 10 & 1,58 \\
\hline Bélgica & 6 & 0,95 \\
\hline França & 6 & 0,95 \\
\hline Espanha & 6 & 0,95 \\
\hline Índia & 5 & 0,79 \\
\hline Escócia & 5 & 0,79 \\
\hline
\end{tabular}

\begin{tabular}{|l|c|c|}
\hline Grécia & 1 & 0,16 \\
\hline Japão & 1 & 0,16 \\
\hline Kuwait & 1 & 0,16 \\
\hline Nova Zelândia & 1 & 0,16 \\
\hline $\begin{array}{l}\text { Irlanda do } \\
\text { Norte }\end{array}$ & 1 & 0,16 \\
\hline Sri Lanka & 1 & 0,16 \\
\hline Taiwan & 1 & 0,16 \\
\hline
\end{tabular}

Fonte: dados coletados de ISI Web of Knowledge. Cálculos dos autores.

A tabela 3 lista os 40 autores mais produtivos entre os 413 artigos da amostra. A liderar Shepherd (16 artigos) é seguido de Zahra (11), Gartner (9), McDougall (8), Wright (7). No top 10 estão ainda Busenitz (7), Fiet (6), Levesque (6), Deeds (6), e Covin (6). Estes são os dez autores mais dinâmicos em termos de publicações na JBV, seguindo as restrições impostas.

Tabela 3. Os 40 autores mais prolíficos

\begin{tabular}{|c|c|c|c|c|c|}
\hline Rank & Autor & Artigos & Rank & Autor & Artigos \\
\hline 1 & Shepherd, D. & 16 & 21 & Westhead, P. & 4 \\
\hline 2 & Zahra, S. & 11 & 22 & Venkataraman, S. & 4 \\
\hline 3 & Gartner, W. & 9 & 23 & Brush, C. & 4 \\
\hline 4 & McDougall, $\mathrm{P}$. & 8 & 24 & Wiklund, J. & 4 \\
\hline 5 & Wright, M. & 7 & 25 & Hisrich, R. & 4 \\
\hline 6 & Busenitz, L. & 7 & 26 & Sarasvathy, S. & 4 \\
\hline 7 & Fiet, J. & 6 & 27 & McGrath, R. & 4 \\
\hline 8 & Levesque, M. & 6 & 28 & North, J. & 4 \\
\hline 9 & Deeds, D. & 6 & 29 & Slevin, D. & 4 \\
\hline 10 & Covin, J. & 6 & 30 & Davidsson, $\mathrm{P}$. & 4 \\
\hline 11 & Kanter, R. & 5 & 31 & Cumming, D. & 4 \\
\hline 12 & Pearce, J. & 5 & 32 & Tan, J. & 4 \\
\hline
\end{tabular}

FERREIRA, M. P.; MIRANDA, R.; REIS, N. R.; PINTO, C. F.; SERRA, F. R. Pesquisa em empreendedorismo no principal periódico internacional: um estudo bibliométrico das publicações no journal of business venturing entre 1987 e 2010. Revista de

Empreendedorismo e Gestão de Pequenas Empresas, v. 3, n.1, p. 56-83, 2014. 


\begin{tabular}{|c|l|c|}
\hline 13 & Honig, B. & 5 \\
\hline 14 & Cooper, A. & 5 \\
\hline 15 & Chrisman, J. & 5 \\
\hline 16 & Chandler, G. & 5 \\
\hline 17 & Shane, S. & 5 \\
\hline 18 & MacMillan, I. & 5 \\
\hline 19 & Sapienza, H. & 5 \\
\hline 20 & Birley, S. & 4 \\
\hline
\end{tabular}

\begin{tabular}{|c|l|c|}
\hline 33 & Dean, T. & 4 \\
\hline 34 & Bates, T. & 4 \\
\hline 35 & Barney, J. & 4 \\
\hline 36 & Baron, R. & 4 \\
\hline 37 & Abetti, P. & 4 \\
\hline 38 & Amit, R. & 4 \\
\hline 39 & Richardson, L. & 3 \\
\hline 40 & Robbins, D. & 3 \\
\hline
\end{tabular}

Fonte: dados coletados de ISI Web of Knowledge. Cálculos pelos autores.

\section{Análise de citações}

$\mathrm{Na}$ análise de citações observam-se as obras que tiveram maior impacto na direção da pesquisa na disciplina nas últimas duas décadas e meia. Na Tabela 4 mostramos apenas as 40 obras mais vezes citadas de entre as 13.721 citações utilizadas pelos 413 artigos da amostra. No topo da Tabela 4, o trabalho de Schumpeter (1934) The theory of economic development, onde expõe o conceito do indivíduo empreendedor e seu papel na geração de inovações, é o mais citado (55 citações). Low e MacMillan (1988), com 52 citações, expandem sobre dimensões da pesquisa em empreendedorismo, como o perfil empreendedor, incubadoras e o capital de risco. Estes trabalhos são seguidos por Shane e Venkataraman (2000) sobre a evolução da disciplina de empreendedorismo, Stinchcombe (1965) sobre a estrutura social e a distribuição de recursos e oportunidades, Vesper (1990) que define empreendedorismo como realizar algo de novo partindo daquilo que é normal ou básico, perseguindo oportunidades, Porter (1980) e as fontes de vantagem competitiva, Gartner (1985) sobre as questões comportamentais como as mais relevantes para pesquisa futura, Venkataraman (1997), Schumpeter (1942) e Sandberg e Hofer (1987) com a proposta que o desempenho da nova empresa é função da estrutura da indústria, da estratégia e do empreendedor fundador. Não é surpreendente que muitos destes trabalhos tenham ais de uma década porque

FERREIRA, M. P.; MIRANDA, R.; REIS, N. R.; PINTO, C. F.; SERRA, F. R. Pesquisa em empreendedorismo no principal periódico internacional: um estudo bibliométrico das publicações no journal of business venturing entre 1987 e 2010. Revista de

Empreendedorismo e Gestão de Pequenas Empresas, v. 3, n.1, p. 56-83, 2014. 
trabalhos mais antigos são mais conhecidos e mais citados, mas salienta-se que vários dos trabalhos nesta listagem são seminais em Administração.

Tabela 4. Os 40 trabalhos mais citados

\begin{tabular}{|c|c|c|c|c|c|}
\hline \# & Autor & $\begin{array}{c}\text { Citações } \\
\text { totais }\end{array}$ & \# & Autor & $\begin{array}{l}\text { Citações } \\
\text { totais }\end{array}$ \\
\hline 1 & Schumpeter (1934) & 55 & 21 & Williamson (1985) & 25 \\
\hline 2 & Low e MacMillan (1988) & 52 & 22 & Knight (1921) & 24 \\
\hline 3 & $\begin{array}{l}\text { Shane e Venkataraman } \\
(2000)\end{array}$ & 51 & 23 & $\begin{array}{l}\text { MacMillan, Siegal e } \\
\text { SubbaNarasimha (1985) }\end{array}$ & 24 \\
\hline 4 & Stinchcombe (1965) & 48 & 24 & $\begin{array}{l}\text { Cooper, Woo e } \\
\text { Dunkelberg (1988) }\end{array}$ & 24 \\
\hline 5 & Vesper (1990) & 44 & 25 & $\begin{array}{l}\text { Cooper, Gimeno- } \\
\text { Gascon e Woo (1994) }\end{array}$ & 23 \\
\hline 6 & Porter (1980) & 40 & 26 & Eisenhardt (1989) & 23 \\
\hline 7 & Gartner (1985) & 37 & 27 & Timmons (1994) & 23 \\
\hline 8 & Venkataraman (1997) & 33 & 28 & Aldrich e Zimmer (1986) & 22 \\
\hline 9 & Schumpeter (1942) & 31 & 29 & $\begin{array}{l}\text { Cohen e Levinthal } \\
(1990)\end{array}$ & 22 \\
\hline 10 & Sandberg e Hofer (1987) & 31 & 30 & $\begin{array}{l}\text { Stevenson e Jarillo } \\
(1990)\end{array}$ & 22 \\
\hline 11 & McClelland (1961) & 29 & 31 & $\begin{array}{l}\text { Eisenhardt e } \\
\text { Schoonhoven (1990) }\end{array}$ & 22 \\
\hline 12 & Barney (1991) & 27 & 32 & Drucker (1985) & 21 \\
\hline 13 & Brockhaus (1980) & 27 & 33 & Brockhaus (1982) & 21 \\
\hline 14 & Kirzner (1973) & 27 & 34 & Nunnally (1978) & 21 \\
\hline 15 & Miller (1983) & 26 & 35 & $\begin{array}{l}\text { Hair, Anderson, Tatham } \\
\text { e Black (1995) }\end{array}$ & 20 \\
\hline 16 & Cohen e Cohen (1983) & 26 & 36 & Birley (1985) & 20 \\
\hline 17 & Penrose (1959) & 25 & 37 & Lumpkin e Dess (1996) & 20 \\
\hline 18 & Busenitz e Barney (1997) & 25 & 38 & Gartner (1988) & 20 \\
\hline 19 & Jensen e Meckling (1976) & 25 & 39 & Aldrich (1999) & 19 \\
\hline 20 & Covin e Slevin (1989) & 25 & 40 & Begley e Boyed (1987). & 19 \\
\hline
\end{tabular}

Fonte: dados coletados da ISI Web of Knowledge.

\section{Análise de cocitações}

A figura 2 representa graficamente as relações de cocitação entre os 40 autores mais citados. Estes são os 40 trabalhos com maior número conjunto de cocitações. A leitura da rede no conjunto, ou de cada par separadamente, permite

FERREIRA, M. P.; MIRANDA, R.; REIS, N. R.; PINTO, C. F.; SERRA, F. R. Pesquisa em empreendedorismo no principal periódico internacional: um estudo bibliométrico das publicações no journal of business venturing entre 1987 e 2010. Revista de

Empreendedorismo e Gestão de Pequenas Empresas, v. 3, n.1, p. 56-83, 2014. 
ganhar uma compreensão geral da importância relativa dada a estes trabalhos (e suas propostas conceituais) pelos 615 autores dos 413 artigos da amostra.

A rede foi feita com o software Ucinet e importa notar na sua leitura que: primeiro, o software coloca os trabalhos de acordo com medidas de proximidade baseadas na frequência de cocitações. Segundo, a posição relativa é uma medida de centralidade relativa. Isto é, em posições mais centrais na rede surgem os trabalhos mais cocitados em termos absolutos. Por exemplo, o trabalho mais central é o de Low e MacMillan (1988). Este trabalho é mais cocitado com Schumpeter (1934), Vesper (1990) e Gartner (1985).

Outros trabalhos, ainda que relevantes, como o de Knight (1921) sobre a percepção de risco e incerteza em novos negócios, ou de Kirzner (1973) ligando empreendedorismo a competitividade, são menos centrais nesta rede relacional, ainda que muito relevantes na literatura existente. Outros laços importantes ligam diversos trabalhos como a análise da indústria e estratégias competitivas de Porter (1980), os estudos de sobrevivência de novas empresas de Stinchcombe (1965), a Visão Baseada em Recursos de Barney (1991) e Penrose (1959), a conceptualização de empreendedorismo e como os indivíduos percepcionam as oportunidades para iniciar uma nova empresa de Venkataraman (1997).

FERREIRA, M. P.; MIRANDA, R.; REIS, N. R.; PINTO, C. F.; SERRA, F. R. Pesquisa em empreendedorismo no principal periódico internacional: um estudo bibliométrico das publicações no journal of business venturing entre 1987 e 2010. Revista de

Empreendedorismo e Gestão de Pequenas Empresas, v. 3, n.1, p. 56-83, 2014. 
Figura 2. Rede de cocitações dos 40 trabalhos mais citados

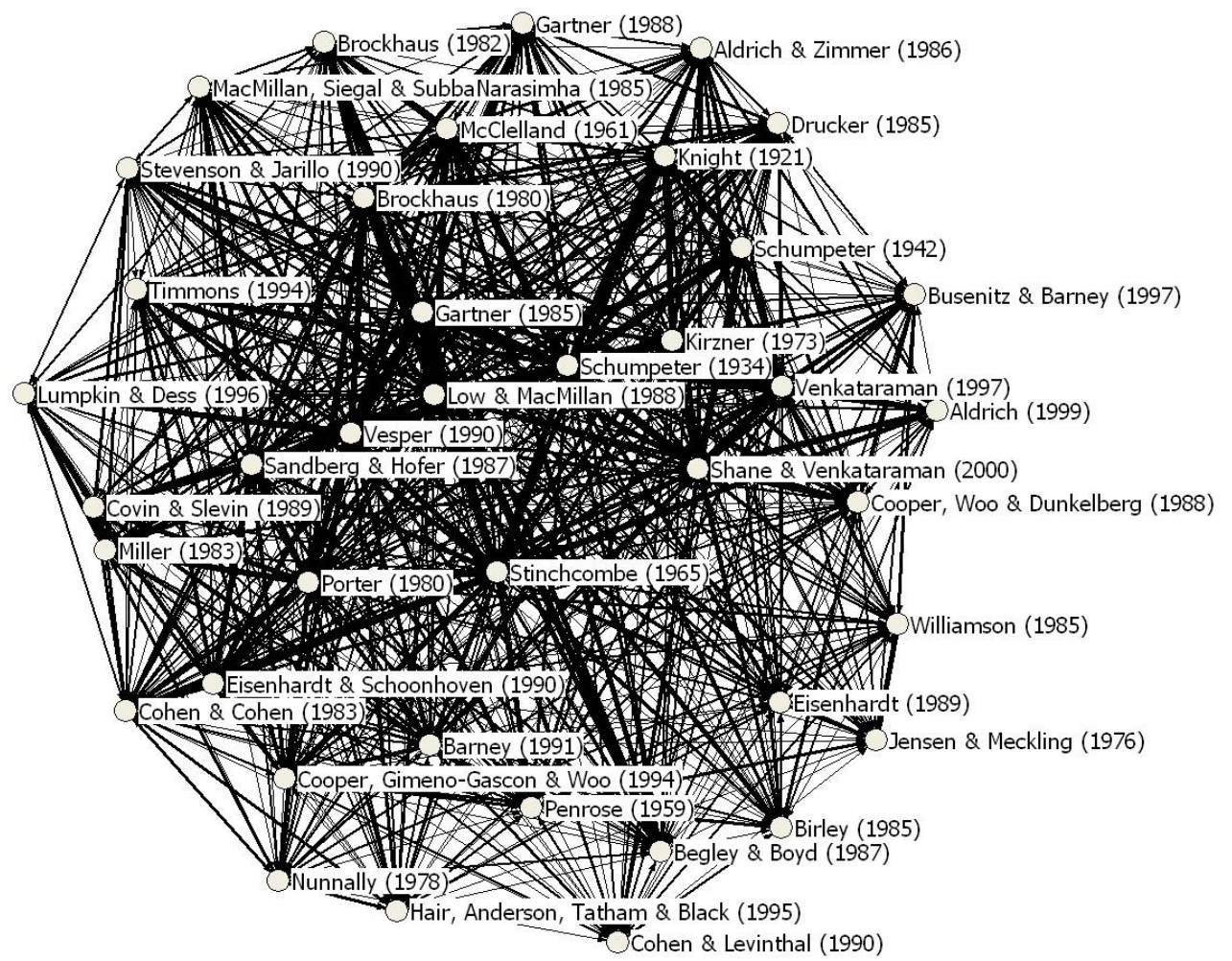

Fonte: dados coletados de ISI Web of Knowledge com Bibexcel. Representação gráfica com Ucinet.

No seu conjunto, os trabalhos inclusos revelam diversos temas e abordagens teóricas, sendo evidência da multidisciplinaridade que tem pautado a pesquisa em empreendedorismo.

\section{Temas de pesquisa}

Para examinar quais os temas de pesquisa seguimos o procedimento já descrito de inferir temas classificando as palavras-chave definidas pelos autores dos artigos. A Figura 3 mostra a rede (network) com os temas, as ligações entre os temas e sua centralidade relativa na pesquisa. Os temas no centro são os mais pesquisados. A espessura das linhas unindo temas é uma medida da força da ligação (strength of the tie) entre os temas. Em essência, a espessura das linhas reflete o número de co-aparências nos artigos publicados, sendo uma proxy para a proximidade intelectual de modo que quanto maior a espessura, maior a ligação, ou

FERREIRA, M. P.; MIRANDA, R.; REIS, N. R.; PINTO, C. F.; SERRA, F. R. Pesquisa em empreendedorismo no principal periódico internacional: um estudo bibliométrico das publicações no journal of business venturing entre 1987 e 2010. Revista de

Empreendedorismo e Gestão de Pequenas Empresas, v. 3, n.1, p. 56-83, 2014. 
proximidade, entre temas. Por exemplo, Entrepreneurial process está mais fortemente ligado com temas como Methods, theories and research issues, revelando que os pesquisadors quando estudam o processo empreendedor se utilizam de aspectos metodológicos e teorias existentes. Outros temas como 'Psychological, cognitive and individual characteristics', 'Value creation and performance' e 'Environmental and external determinants of entrepreneurship', são aqueles com maior proximidade intelectual.

Figura 3. Principais temas em rede relacional

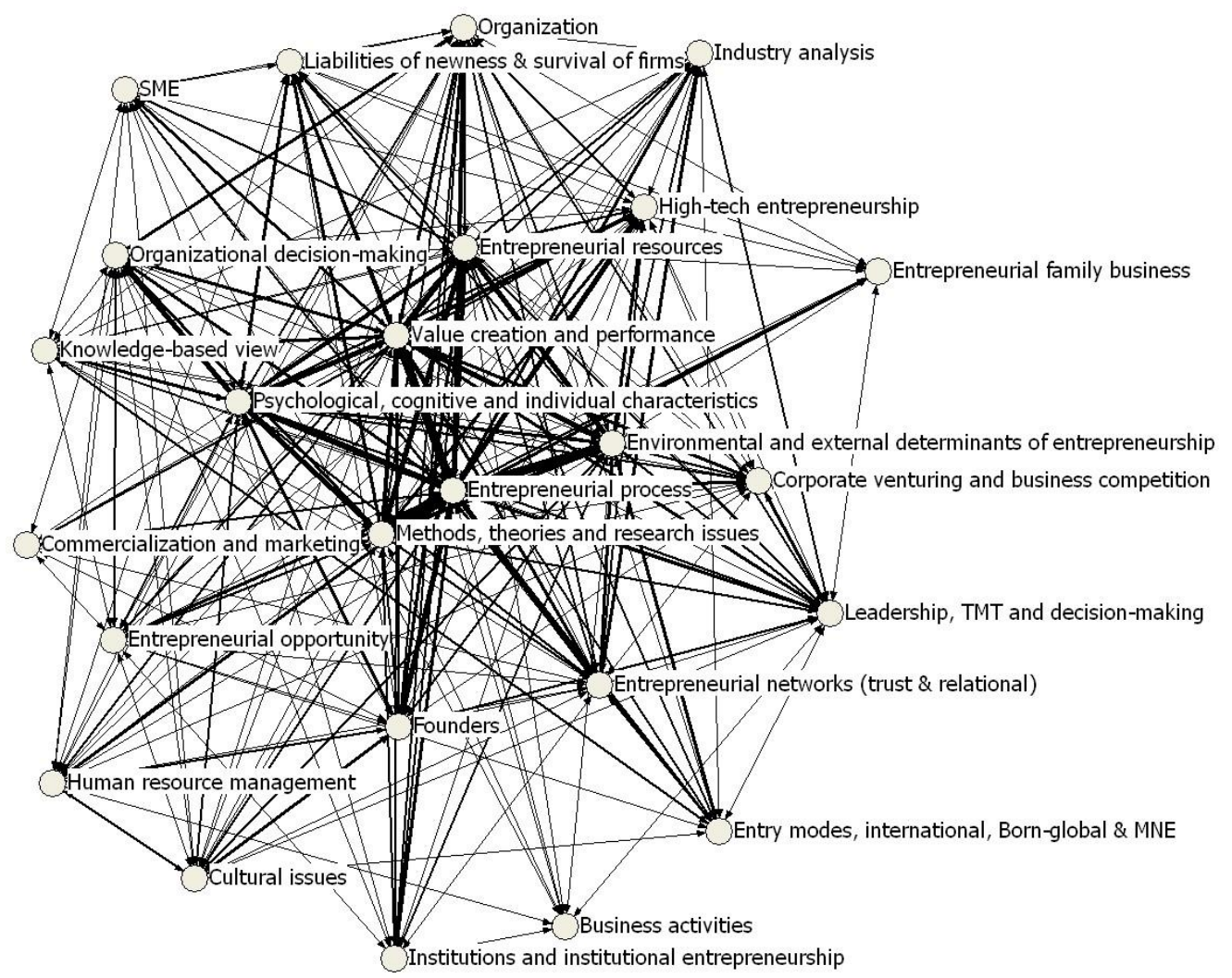

Fonte: dados coletados de ISI Web of Knowledge com Bibexcel. Representação gráfica com Ucinet.

Em resumo, a figura 3 revela não apenas os temas, mas também a proximidade intelectual com que têm sido utilizados na pesquisa e a frequência com que têm sido tratados nos artigos publicados no JBV. Sendo este o principal periódico na disciplina, é razoável sugerir que estes têm sido os principais temas na pesquisa em empreendedorismo mais genericamente.

FERREIRA, M. P.; MIRANDA, R.; REIS, N. R.; PINTO, C. F.; SERRA, F. R. Pesquisa em empreendedorismo no principal periódico internacional: um estudo bibliométrico das publicações no journal of business venturing entre 1987 e 2010. Revista de

Empreendedorismo e Gestão de Pequenas Empresas, v. 3, n.1, p. 56-83, 2014. 


\section{DISCUSSÃo}

Neste artigo visámos entender melhor o estoque de conhecimento acumulado em empreendedorismo. Metodologicamente conduzimos um estudo bibliométrico no principal periódico da área - o Journal of Business Venturing, examinando uma amostra dos artigos publicados ao longo de 24 anos, entre 1987 e 2010. As análises envolveram identificar os autores mais produtivos (os que mais publicaram), a origem dos trabalhos, os trabalhos mais citados, as relações de cocitação entre obras e os temas pesquisados. Este tipo de estudo é especialmente relevante para estudantes de doutorado e jovens acadêmicos ainda menos familiarizados com a pesquisa da disciplina para, a partir desta sistematização, desenharem as suas agendas de pesquisa. Simultaneamente, encontram neste trabalho indicações sobre as principais referências da área.

Os resultados do estudo mostram que a pesquisa tem estado fortemente concentrada em pesquisadores norte-americanos, que foram (co)autores em 389 artigos (412 artigos na amostra). Também observamos que cerca de dois terços da pesquisa está concentrada nos EUA, Canadá e Inglaterra, além de outros países europeus. Estes dois resultados podem ser evidência do interesse, inclusive por motivos de política pública, que é dado à pesquisa nestes países. No entanto, mas não podemos desconsiderar que, quando analisamos a pesquisa publicada em periódicos internacionais, pode haver maiores dificuldades de publicar para pesquisadores não nativos na língua inglesa.

A produtividade dos pesquisadores revelou que um pequeno grupo de autores tem várias publicações e que a maioria publicou apenas um artigo. Os autores mais produtivos foram Shepherd, Zahra, Gartner, McDougall, Wright, Busenitz, Fiet, Levesque, Deeds e Covin. Estes são pesquisadores bem reputados na disciplina mas apenas Covin, Busenitz e Gartner têm trabalhos entre os mais citados. Assim, também fica evidente que há uma diferença entre o ser um acadêmico prolífico e um acadêmico com impacto. No entanto, é previsível que o impacto destes autores aumente gradualmente, porque a pesquisa em empreendedorismo verifica uma tendência ascendente. 
A rede de cocitações (Figura 3) mostra os trabalhos mais centrais na pesquisa, revelando as conexões intelectuais entre autores ou obras. No centro da rede surgem trabalhos como Schumpeter (1934), Low e MacMillan (1988), Gartner (1985), Stinchcombe (1965) e Vesper (1990). Estes parecem ser os trabalhos com maior impacto na pesquisa. Mas, observando a rede de cocitações encontramos vários outros trabalhos que sinalizam virtualmente todas as principais teorias da Administração, incluindo a Teoria dos Custos e Transação, Visão Baseada nos Recursos, Redes sociais, Aprendizagem, Teoria da Agência, abordagens comportamentais e da indústria. Os trabalhos na rede também ilustram diferentes contextos em que estudos de empreendedorismo têm vindo a ser realizados. No entanto, a avaliação dos contextos foi feita com a identificação dos temas e construção da rede relacional entre temas (Figura 4).

Os temas pesquisados em empreendedorismo têm sido bastante diversos. No essencial, é evidente que os temas identificados retratam efetivamente a pesquisa em empreendedorismo. Observamos, na Figura 4, que os temas mais centrais têm sido pertinentes ao processo empreendedor, questões metodológicas, aspectos psicológicos e cognitivos e as características individuais, a criação de valor e os fatores do ambiente externo enquanto determinantes do empreendedorismo. Outros temas têm sido menos explorados, ocupando posições relativamente mais periféricas na rede, como sejam as pequenas e médias empresas, o empreendedorismo institucional, organização, gestão de recursos humanos. Vários destes aspetos que tendemos a associar talvez mais à gestão de pequenas empresas. A nossa análise não contemplou qualquer distinção longitudinal pelo que não é possível discutir como pode ter vindo a haver alguma mudança na orientação da disciplina. Efetivamente, ao analisarmos o estoque de conhecimento não incluímos medidas de fluxo.

Da análise dos temas fica evidente que alguns têm sido menos explorados pelo que, potencialmente, têm o potencial de ser campos para pesquisa futura. Genericamente, estes são os na periferia da rede (Figura 4) como o empreendedorismo internacional, o impacto do ambiente institucional na criação de novas empresas, os aspectos culturais para além das características individuais, os

FERREIRA, M. P.; MIRANDA, R.; REIS, N. R.; PINTO, C. F.; SERRA, F. R. Pesquisa em empreendedorismo no principal periódico internacional: um estudo bibliométrico das publicações no journal of business venturing entre 1987 e 2010. Revista de

Empreendedorismo e Gestão de Pequenas Empresas, v. 3, n.1, p. 56-83, 2014. 
processos empreendedores nas empresas familiares, a tomada de decisão pelos empreendedores, entre outros.

\section{Limitações e pesquisa futura}

Este estudo tem limitações, algumas derivadas do próprio método utilizado. A escolha de um único periódico, ainda que o periódico líder, restringe o escopo da análise e resultados porque apenas capturamos uma pequena parte de todos os estudos e pesquisas publicados. Pesquisa futura poderá envolver uma análise expandida a, por exemplo, outros periódicos de modo a entender não apenas a pesquisa num periódico, mas sim a pesquisa na disciplina. É possível que sejam identificados novos padrões e conexões usando uma amostra mais alargada. Enquanto é pouco provável que os artigos publicados no JBV não sejam um retrato fiel da pesquisa na disciplina, um estudo mais extenso permitirá identificar outros fatores e outras teorias específicas a outras disciplinas, desde o marketing ao comportamento organizacional. Ainda assim, ao selecionar um periódico líder, este artigo foca na pesquisa mais visível e, previsivelmente, a mais citada, o que é um fator de confiança que o estudo capta uma amostra representativa de pelo menos os trabalhos com maior impacto na disciplina. De forma similar, a delimitação do estudo a artigos deixa de fora outros documentos como teses e dissertações, relatórios técnicos, entre outros, que podem conter insights importantes. Assim, novas pistas para pesquisa futura também podem advir de extensões a outros tipos de documentos.

Outras limitações são específicas aos procedimentos utilizados. Embora análises de citações e cocitações sejam frequentemente usadas, a realidade é que não é possível sem análises de conteúdo mais profundas saber quais as razões porque uma dada citação é feita. Por vezes, um autor cita outro trabalho para construir sobre ele, outras vezes para o criticar e ainda outras para contrastar os resultados ou abordagens conceituais. Ademais, ao escrutinar frequências de citações é relevante entender que pode haver algum viés para trabalhos mais antigos. Previsivelmente, trabalhos mais antigos serão mais conhecidos e terão 
maior número de citações. Por exemplo, na tabela 4 notamos que entre os trabalhos mais citados não consta nenhum publicado na última década. Por outro lado, é difícil interpretar cocitações para além da observação que um dado par de trabalhos é cocitado e a frequência com que ocorre a cocitação. Embora seja razoável a assunção que a cocitação é uma proxy adequada da proximidade intelectual (RAMOS-RODRIGUEZ; RUIZ-NAVARRO, 2004), investigação futura poderia utilizar técnicas estatísticas e de análises de conteúdo para melhor interpretar os laços entre trabalhos.

Neste artigo, o conteúdo dos trabalhos é analisado de forma sumária, através das palavras-chave fornecidas pelos autores (seguindo a proposta de Furrer et al. (2008)). Seria interessante desagregar esta análise para questões como os métodos usados, os contextos e as amostras empíricas. É, também, pertinente notar que as categorias, ou temas, não são necessariamente mutuamente exclusivas e pode haver alguma subjetividade na codificação das palavras-chave. Adicionalmente, cada artigo pode ser classificado em mais do que um tema o que, sendo razoável, porque um artigo pode tratar uma teoria, um contexto e um método simultaneamente, pode dificultar uma análise integradora. Pesquisa futura pode visar identificar apenas um tema a cada artigo e construir a partir deste a estrutura intelectual da disciplina.

\section{COMENTÁRIO FINAL}

Para os pesquisadores há um valor intrínseco que emerge de estudos bibliométricos e de revisão de literatura, na medida que permitem ganhar uma compreensão geral do estoque de conhecimento acumulado. Neste estudo o conhecimento refere-se à pesquisa em empreendedorismo, que é uma disciplina ainda relativamente recente na área da Administração, nomeadamente no Brasil. Uma evidência é o pequeno número de periódicos especializados que existe no Brasil. Mas, os benefícios do estudo estendem-se para além da sistematização do que já foi estudado e entender o conhecimento existente permite, talvez mais especialmente a jovens pesquisadores e estudantes de mestrado e doutorado 
entender a estrutura do conhecimento e os espaços ainda pouco explorados. As lacunas no conhecimento são objetivas oportunidades para novos estudos. Talvez no caso brasileiro exista ainda toda uma plêiade de estudos que são necessários para entender como o contexto - certamente o cultural e social mas de forma mais abrangente o contexto institucional - é influenciador de empreendedorismo. As inúmeras lacunas e espaços insuficientemente explorados permitem antever que a disciplina continuará em forte crescimento no Brasil e, previsivelmente o desenvolvimento institucional aportará novos cursos de mestrado e doutorado em empreendedorismo, a criação de centros e agências e inclusive periódicos especializados.

\section{REFERÊNCIAS}

ACEDO, F.; BARROSO, C.; GALAN, J. The resource-based theory: Dissemination and main trends, Strategic Management Journal, v. 27, p. 621-636, 2006.

ALDRICH, $\mathrm{H}$. The emergence of entrepreneurship as an academic field: A personal essay on institutional entrepreneurship, Research Policy, v. 41, p. 1240-1248, 2012.

ALDRICH, H. Organizations evolving. Thousand Oaks, California: Sage, 1999.

ALDRICH, H.; ZIMMER, C. Entrepreneurship through social networks. In Sexton, D. \& Smilor, R. (Eds.), The art and science of entrepreneurship, Cambridge, MA: Ballinger, p. 3-23, 1986.

BARNEY, J. Firm resources and sustained competitive advantage. Journal of Management, v. 17, n. 1, p. 99-120, 1991.

BEGLEY, T.; BOYD, D. Psychological characteristics associated with performance in entrepreneurial firms and smaller businesses. Journal of Business Venturing, v. 2, n. 2, p. 79-93; 1987.

BIRLEY, S. The role of networks in the entrepreneurial process, Journal of Business Venturing, v. 1, n. 1, p. 107-117, 1985.

BROCKHAUS, R. Risk taking propensity of entrepreneurs. Academy of Management Journal, v. 23, n. 3, p. 509-520, 1980.

BROCKHAUS, R. The psychology of the entrepreneur. In Kent, C., Sexton, D. e Vesper, K. Encyclopedia of Entrepreneurship, Prentice Hall, p. 39-57, 1982.

FERREIRA, M. P.; MIRANDA, R.; REIS, N. R.; PINTO, C. F.; SERRA, F. R. Pesquisa em empreendedorismo no principal periódico internacional: um estudo bibliométrico das publicações no journal of business venturing entre 1987 e 2010. Revista de

Empreendedorismo e Gestão de Pequenas Empresas, v. 3, n.1, p. 56-83, 2014. 
BUSENITZ, L.; BARNEY, J. Differences between entrepreneurs and managers in large organizations: Biases and heuristics in strategic decision-making, Journal of Business Venturing, v. 12, n. 6, p. 9-30, 1997.

BUSENITZ, L.; WEST, G.; SHEPHERD, D.; NELSON, T.; CHANDLER, G.; ZACHARAKIS, A. Entrepreneurship research in emergence: Past trends and future directions. Journal of Management, v. 29, p. 285-308, 2003.

COHEN, J.; COHEN, P. Applied multiple regression/correlation analysis for the behavioural sciences, $2^{\text {nd }}$ ed., Hillsdale, NJ: Erlbaum, 1983.

COHEN, W.; LEVINTHAL, D. Absorptive capacity: A new perspective on learning and innovation, Administrative Science Quarterly, v. 35, p. 128-152, 1990.

COOPER, A.; GIMENO-GASCON, F.; WOO, C. Initial human and financial capital as predictors of new venture performance, Journal of Business Venturing, v. 9, p. 371-395, 1994.

COOPER, A.; WOO, C.; DUNKELBERG, W. Entrepreneurs' perceived chances for success, Journal of Business Venturing, v. 3, n. 2, p. 97-108, 1998.

COOPER, A. Entrepreneurship: The past, the present, the future. in Acs \& Audretsch, Handbook of Entrepreneurship Research: An Interdisciplinary Survey and Introduction. Boston: Kluwer Academic Publishers, p. 21-34, 2003.

CORNELIUS, B.; LANDSTRÖM, H.; PERSSON, O. Entrepreneurial studies: The dynamic research front of a developing social science, Entrepreneurship Theory and Practice, v. 30, n. 3, p. 375-398, 2006.

COVIN, J.; SLEVIN, D. Strategic management of small firms in hostile and benign environments, Strategic Management Journal, v. 10, n. 1, p. 75-87, 1989.

DAVIDSSON, P. The domain of entrepreneurship research: Some suggestions, in Katz, J. e Shepherd, D. (Eds.) Cognitive Approaches to Entrepreneurship Research (Advances in Entrepreneurship, Firm Emergence and Growth, Volume 6), Emerald Group Publishing Limited, p. 315-372, 2003.

DÉRY, R.; TOULOUSE, J.-M. Social structuration of the field of entrepreneurship: a case study. Canadian journal of administrative sciences, v. 13, n. 4, p. 285-305, 1996.

DIODATO, V. Dictionary of bibliometrics, Haworth Press: Binghamton, NY, 1994.

DRUCKER, P. Innovation and entrepreneurship: Practice and principles. Heinemann, London, 1985.

FERREIRA, M. P.; MIRANDA, R.; REIS, N. R.; PINTO, C. F.; SERRA, F. R. Pesquisa em empreendedorismo no principal periódico internacional: um estudo bibliométrico das publicações no journal of business venturing entre 1987 e 2010. Revista de

Empreendedorismo e Gestão de Pequenas Empresas, v. 3, n.1, p. 56-83, 2014. 
EISENHARDT, K. Building theories from case study research, Academy of Management Review, v. 14, n. 4, p. 532-550, 1989.

EISENHARDT, K.; SCHOONHOVEN, C. Organizational growth: Linking founding team, strategy, environment, and growth among U.S. semiconductor ventures, Administrative Science Quarterly, v. 35, p. 504-529, 1990.

FERREIRA, M. A bibliometric study on Ghoshal's managing across borders, Multinational Business Review, v. 19, n. 4, p. 357-375, 2011.

FURRER, O.; TOMAS, H.; GOUSSEVSKAIA, A. The structure and evolution of the strategic management field: A content analysis of 26 years of strategic management research, International Journal of Management Reviews, v. 10, n. 1, p. 1-23, 2008.

GARTNER, W. A conceptual framework for describing the phenomenon of new venture creation, Academy of Management Review, v. 10, n. 4, p. 696-706, 1985.

GARTNER, B. Who is an Entrepreneur? Is the wrong question, American Journal of Small Business, v. 12, n. 40, p. 543-556, 1988.

GARTNER, W.; DAVIDSSON, P.; ZAHRA, S. Are you talking to me? The nature of community in entrepreneurship scholarship, Entrepreneurship Theory and Practice, v. 30, n. 3, p. 321-331, 2006.

GRÉGOIRE, D.; NOËL, M.; DÉRY, R.; BÉCHARD, J. Is there conceptual convergence in entrepreneurship research? A co-citation analysis of frontiers of entrepreneurship research, 1981-2004, Entrepreneurship Theory and Practice, v. 30, n. 3, p. 333-373, 2006.

HAIR, J.; ANDERSON, R.; TATHAM, R.; BLACK, W. Multivariate data analysis with readings, Englewood Cliffs, NJ: Prentice-Hall, 1995.

HARZING, A-W. Journal Quality List 2011, 38 ${ }^{\text {th }}$ edition, 4 February, 2011.

JENSEN, M.; MECKLING, W. Theory of the firm: Managerial behavior, agency costs and ownership structure, Journal of Financial Economics, v. 3, n. 4, p. 305-360, 1976.

KEUPP, M.; GASSMANN, $O$. The past and the future of international entrepreneurship: A review and suggestions for developing the field, Journal of Management, v. 35, n. 3, p. 600-633, 2009.

KIRZNER, I. Competition and entrepreneurship, Chicago, IL: University of Chicago Press, 1973.

KNIGHT, F. Risk, uncertainty and profit, New York: Harper, 1921.

FERREIRA, M. P.; MIRANDA, R.; REIS, N. R.; PINTO, C. F.; SERRA, F. R. Pesquisa em empreendedorismo no principal periódico internacional: um estudo bibliométrico das publicações no journal of business venturing entre 1987 e 2010. Revista de

Empreendedorismo e Gestão de Pequenas Empresas, v. 3, n.1, p. 56-83, 2014. 
KRAUS, S. State-of-the-art current research in international entrepreneurship: A citation analysis, African Journal of Business Management, v. 5, n. 3, p. 10201038, 2011.

LOW, M. The adolescence of entrepreneurship research: Specification of purpose. Entrepreneurship Theory and Practice, v. 26, n. 4, p. 17-25, 2001.

LOW, M.; MACMILLAN, I. Entrepreneurship: Past research and future challenges, Journal of Management, v. 14, p. 139-161, 1988.

LUMPKIN, G.; DESS, G. Clarifying the entrepreneurial orientation construct and linking it to performance, Academy of Management Review, v. 21, n. 1, p. 135-172, 1996.

MACMILLAN, I.; SIEGAL, R.; SUBBANARASIMHA, P. Criteria used by venture capitalists to evaluate new venture proposals, Journal of Business Venturing, v. 1, p. 119-128, 1985.

MCCLELLAND, D. The achieving society. Princeton, NJ: Van Nostrand, 1961.

MILLER, D. The correlates of entrepreneurship in three types of firms, Management Science, v. 29, n. 7, p. 770-791, 1983.

NICHOLLS, A. The legitimacy of social entrepreneurship: reflexive isomorphism in a pre-paradigmatic field. Entrepreneurship theory and practice, v. 34, p. 611-633, 2010.

NUNNALLY, J. Psychometric theory, New York: McGraw Hill, 1978.

PENROSE, E. The theory of the growth of the firm, New York: John Wiley, 1959.

PORTER, M. Competitive strategy. Free Press: New York, 1980.

RAMOS-RODRÍGUEZ, A.; RUÍZ-NAVARRO, J. Changes in the intellectual structure of strategic management research: A bibliometric study of the Strategic Management Journal, 1980-2000, Strategic Management Journal, v25, n. 10, p. 981-1004, 2004.

RATNATUNGA, J.; ROMANO, C. A citation classics' analysis of articles in contemporary small enterprise research, Journal of Business Venturing, v. 12, n. 3, p. 197-212, 1997.

SCHILDT, H.; ZAHRA, S.; SILLANPAA, A. Scholarly communities in entrepreneurship research: $A$ co-citation analysis, Entrepreneurship Theory and Practice, v. 30, n. 3, p. 399-415, 2006.

FERREIRA, M. P.; MIRANDA, R.; REIS, N. R.; PINTO, C. F.; SERRA, F. R. Pesquisa em empreendedorismo no principal periódico internacional: um estudo bibliométrico das publicações no journal of business venturing entre 1987 e 2010. Revista de

Empreendedorismo e Gestão de Pequenas Empresas, v. 3, n.1, p. 56-83, 2014. 
SANDBERG, W.; HOFER, C. Improving new venture performance: The role of strategy, industry structure and the entrepreneur, Journal of Business Venturing, $v$. 2, n. 1, p. 5-28, 1987.

SCHUMPETER, J. The theory of economic development, Cambridge, Mass: Harvard University Press, 1934.

SCHUMPETER, J. Capitalism, socialism and democracy. Harper \& Row, New York, 1942.

SHAFIQUE, M. Thinking inside the box? Intellectual structure of the knowledge base of innovation research (1988-2008). Strategic Management Journal, v. 34, p. 6293, 2013.

SHANE, S.; VENKATARAMAN, S. The promise of entrepreneurship as a field of research, Academy of Management Review, v. 25, p. 217-226, 2000.

SHANE, S. Who is publishing the Entrepreneurship research?, Journal of Management, v. 23, p. 83-95, 1997.

SHANE, S. Prior knowledge and the discovery of entrepreneurial opportunities, Organization Science, v. 11, p. 448-469, 2000.

SMALL, H.; GRIFFITH, B. C. The structure of scientific literatures I: identifying and graphing specialties. Sciences studies, v. 4, n. 1, p. 17-40, 1974.

STEVENSON, H.; JARILLO, J. A paradigm of entrepreneurship: Entrepreneurial management, Strategic Management Journal, v. 11, p. 17-27, 1990.

STINCHCOMBE, A. Social structure and organizations. In March, J. (Ed.), Handbook of Organizations, 142-193, Chicago: Rand McNally, 1965.

TEIXEIRA, A. Mapping the (in)visible college(s) in the field of entrepreneurship. Scientometrics, v. 89, p. 1-36, 2011.

TIMMONS, J.A.; SPINELLI, S. New venture creation: entrepreneurship for the $21^{\text {st }}$ century. (v. 4). Boston: Irwin, 1994.

VENKATARAMAN, S. The distinctive domain of entrepreneurship research. In Katz, J. (Ed.) Advances in entrepreneurship, firm emergence and growth, Greenwich, CN: JAI Press, p. 119-138, 1997.

VESPER, K. New venture strategies, Prentice Hall, Englewood Cliffs, N.J, 1990.

WHITE, D.; MCCAIN, K. Visualizing a discipline: An author co-citation analysis of information science, 1972-1995. Journal of the American Society for Information Science, v. 49, p. 327-355, 1998.

FERREIRA, M. P.; MIRANDA, R.; REIS, N. R.; PINTO, C. F.; SERRA, F. R. Pesquisa em empreendedorismo no principal periódico internacional: um estudo bibliométrico das publicações no journal of business venturing entre 1987 e 2010. Revista de

Empreendedorismo e Gestão de Pequenas Empresas, v. 3, n.1, p. 56-83, 2014. 
WHITE, H.; GRIFFITH, B. Author co-citation: A literature measure of intellectual structure. Journal of the American Society for Information Science, v. 32, p. 163$171,1981$.

WILLIAMSON, O. The economic institutions of capitalism, New York: Free Press, 1985.

\section{ANEXO. Principais temas pesquisados}

\begin{tabular}{ll}
\hline & Business start-up; entrepreneurial action; entrepreneurial activity; entrepreneurial \\
& commitment; Entrepreneurial information processing; entrepreneurial learning; \\
& entrepreneurial process; entrepreneurial search process; entrepreneurial theory; \\
& Entrepreneurial transition; entrepreneurship education; entrepreneurship textbooks; \\
Entrepreneurial & entrepreneurship theory; nascent activity; nascent entrepreneurship; new venture creation; \\
process $(n=93)$ & Schumpeterian entrepreneur; start-up formation; start-up process; business start-up \\
& assistance; planning; Early stage focus; entrepreneurship chairs; entrepreneurship \\
& endowments; latent entrepreneurship; trigger; phase transition; business ideas; business \\
& plans; Small business entrepreneurship; Creation entrepreneurship; entrepreneurship; \\
& entrepreneurial firms; entrepreneurial start-ups; new ventures; start-ups; emergence; \\
& emerging organizations; entrepreneurship programs; organizational founding.
\end{tabular}
izations; entrepreneurship programs; organizational founding.

Entrepreneurial finance; entrepreneurial rents; angel capital; angel investing; angels; capital; capital pool; capital structure; cash crisis; financial contracts; financial indicators; financial position; financing; financing strategy; venture capital; venture capital cycle; venture capital involvement; venture capitalist; venture capitalists; real options; real options theory; small Entrepreneurial firm finance; bootstrapping; equity financing; going public; infrastructure; initial resources resources $(n=70)$ and decisions; IPO; private equity; start-up finance; women business angels; entrepreneurship support; business angel; business assistance; seed funds; corporate governance; dual track; government sponsorship; incentives; temporal stability; slack; corporate venture capital; resource dependence; weak tie investment; syndication; risk capital; funding strategy.

Attitudes; comparative optimism; confidence; emotion; emotional displays; emotions; entrepreneurial behaviour; entrepreneurial cognition; inspiration; personal strain; personality; personality of entrepreneurs; psychological ownership; risk perception; risk propensity;

Psychological, cognitive and individual characteristics $(n=68)$ affect heuristic; alertness; intelligence; prediction; moral imagination; the big five; cognitive and constructionist perspectives; hindsight bias; cognitive comprehensiveness; cognitive perspective; cognition; risk; uncertainty; double moral hazard; environmental uncertainty; entrepreneurial experience; sequential (serial) and portfolio entrepreneurs; perceptions; persistence; resilience; self-interests; English; proficiency; experiences; champion; commitment; habitual (repeat) entrepreneurs; aging; antecedents; creativity; ignorance reduction; outcome expectations; public interventions; successful intelligence; education; entrepreneurial intention; entrepreneurial intentions; identity complexity.

Development; developmental phase; economic growth; growth cycle; growth of the firm; growth patterns; growth strategy; incrementally; size; economic performance; firm growth; firm performance; founder performance; growth; high growth; high growth firms; new firm

Value creation and performance $(n=66)$

Environmental and external determinants of entrepreneurship $(n=59)$ performance; new venture performance; organizational performance; performance; performance consequence; resource theory; resource-based; resource-based view; efficiency; timing of exploitation; dynamic capabilities; competence; successful entrepreneurship; sustainable entrepreneurship; dynamics; dynamism; sustainability; sustainability orientation; portfolio diversification; normalization; stagnation; Tobin's q; ROE; capabilities; capability; firm resources; organizational response; entrepreneurial resource; sell-out; sustainable development; successful closure.

Entrepreneurial environment; entrepreneurship centers; Environmental entrepreneurship; social entrepreneurship; Chinese enterprise reform; public policy; social context; social norms; social wealth; agglomeration; Brazil; China; environment; environmental behaviour; genetic and environmental influences; geographic clusters; geographic scope; government; India; location; national context; Nigeria; Norway; Poland; Russia; urban areas; Vietnam; environment-strategy coevolution; context of entrepreneurial phenomena; business incubators; regulatory focus; generative rules; illegality; informational-economics; local renewal; crowding out; economic transformation; situational constraints; emerging markets;

FERREIRA, M. P.; MIRANDA, R.; REIS, N. R.; PINTO, C. F.; SERRA, F. R. Pesquisa em empreendedorismo no principal periódico internacional: um estudo bibliométrico das publicações no journal of business venturing entre 1987 e 2010. Revista de

Empreendedorismo e Gestão de Pequenas Empresas, v. 3, n.1, p. 56-83, 2014. 
transition economy; transition/emergeng economy; economic freedom; economic reform; tax; control of corruption; license raj; protection of private properties; corruption; welfare.

Methods, theories and research issues $(n=59)$

Economic theories of entrepreneurship; entrepreneurship journals; entrepreneurship research; 1997 National Family Business Survey; algorithmic and heuristic information processing; case study; game theory; genetic covariance;; literature review; longitudinal methods; mathematics; optimization model; panel data; Prospect theory; questionnaire experiment; regulatory focus theory; research; social exchange theory; social theory; structuration theory; theory; theory building; theory of planned behaviour; time series; typologies; agency; conjoint experiment; cox proportional hazards model; role modelling; sample; structural equation model; Structural equation modelling; Prisoner's dilemma; BayhDole Act; convergent validity; publications glut; scholar; staging; theory of the firm; valuation; ecosystem perspective; guided preparation; transaction cost theory; metaphor; option grant depth; panel attrition; retrospective recall; source; effectuation; opportunism; moderators.

Innovation and entrepreneurship; new technology-based ventures; breakthrough innovation; creation; external technology sourcing; high-technology entrepreneurship; Imitators;

High-tech entrepreneurship $(n=33)$ Innovation; new product development; new products; portfolio; property rights; R\&D; R\&D alliances; spillover; spin-glass simulations; technology development projects; technology transfer; expertise; technological capabilities; novelty; research-based spin-off; behaviour genetics; universities; university; university patenting.

Entrepreneurial control; entrepreneurial team; entrepreneurial team formation; leadership;

Leadership, TMT boards; boards of directors; business owners; decision; early stage team activities; employee ownership; employee stock options; managerial levels; managers; new venture management; organizational tenure; small business management; team diversity; team heterogeneity; team outcomes; executive compensation; manager departure; upper echelons; status quo bias.

making $(\mathrm{n}=30)$

Entrepreneurial alliances; business networks; institutions networks; interorganizational

Entrepreneurial networks (trust \& relational $)(n=30)$ relationships; network; network effect; network theory; networked incubators; networking; networks; social capital; social networks; strategic alliance; strategic alliances; trust; particularistic and system trust network and social capital; cohesion; co-production; identity centrality; alliance contracts; behaviour; alliance design; alliances; social capital theory; exchange partners; interorganizational.

Entrepreneur; expert entrepreneurs; founders; founding; founder-managed business; nascent entrepreneur; nascent entrepreneurs; self-employed; self-employment; women

Founders $(n=28) \quad$ entrepreneurs; entrepreneurs; founder characteristics; founder role identity; entrepreneurial status; non-farm proprietor employment; sense making; habitual (repeat) entrepreneurs; university incubates; academics; unemployment; illegal entrepreneurship; research scientists/engineers; founder CEOs; career choice;

Fit; open organizational context; organisational crisis; organization; organization design; organizational ambient; organizational behaviour; organizational characteristics; organizational creation; organizational design; formal and informal integration mechanisms;

Organization organizational environment; conflict; constructive deviance; loose coupling; organizational $(n=27)$ entrainment; time allocation; contract enforcement; contract negotiations; governance structure; governance; ownership structure; governance modes; structural differentiation; control.

Entrepreneur decision-making; entrepreneurial decisions; action; anchoring-and-adjustment

Organizational heuristic; asymmetric information; information acquisition; moral hazard; optimal stopping; decision-making strategic reactiveness; bounded rationality; information utilization; perpetual reasoning; $(\mathrm{n}=22)$ decision making; decision-making; decision-making processes; decision model; improvisation.

Entrepreneurial identification; nexus of entrepreneur and opportunity; entrepreneurial Entrepreneurial opportunity; Entrepreneurial opportunity identification; Entrepreneurial opportunity opportunity $(n=19)$ perception; entrepreneurial orientation; opportunities; opportunity; opportunity exploitation; opportunity recognition; opportunity research; opportunity search; rule breaking.

\begin{tabular}{ll}
\hline Corporate & Corporate sustainability; corporate entrepreneurship; corporate venturing; business \\
venturing and & practices; new venture strategy; entrepreneurial strategy; critical success; factors; harvest \\
business & strategy; small business strategy; hyper competition; strategic behaviour; market \\
competition & imperfections.
\end{tabular}

FERREIRA, M. P.; MIRANDA, R.; REIS, N. R.; PINTO, C. F.; SERRA, F. R. Pesquisa em empreendedorismo no principal periódico internacional: um estudo bibliométrico das publicações no journal of business venturing entre 1987 e 2010. Revista de

Empreendedorismo e Gestão de Pequenas Empresas, v. 3, n.1, p. 56-83, 2014. 
$(\mathrm{n}=17)$

Liabilities of

newness \& survival of firms

$(n=17)$

Entry modes,

international,

Born-global \&

MNE $(n=16)$

Cultural issues

$(n=16)$

Human resource management

$(n=16)$

Knowledge-based view $(n=15)$

Industry analysis $(n=14)$

Institutions and

institutional

entrepreneurship

$(n=12)$

Entrepreneurial family business

$(n=11)$

Small and Medium

Enterprises ( $\mathrm{n}=10)$

Commercialization

and marketing

$(\mathrm{n}=7)$

Business activities

$(\mathrm{n}=5)$

Under-pricing; small business capital markets; marketing; market augmenting; customer knowledge; foreign sales base; marketing mix; market information.

Nota: Em parêntesis a frequência de palavras-chave.

Artigo recebido em: 05/09/2013. Artigo aprovado em: 31/10/2013.

Business failure; business failure experience; exit; venture exits; entrepreneurial exit; entrepreneurial transformation; survival; external and relational uncertainty; legitimization; liabilities of newness; liability of newness; new venture survival; business demise; unsuccessful closure; opportunity costs;

Export; internationalisation; international joint ventures; international venturing; internationalization; market failure; typology of international ventures; international entrepreneurship; internationalization strategy; cross-border trading; cross-national study; external evaluation; foreign stock listing.

Cultural and institutional context; culture; female; gender; gender identity; guanxi and relationship during Chinese institutional transition; Hispanic; male; psychic distance; racial groups; ethical standards; ethics; segregation; framing; intergenerational correlation.

Career paths; career satisfiers; careers; human capital; human capital programs; human practices; middle managers; promotion focus; career anchors; ability expectations.

Knowledge; knowledge management; knowledge spillovers; knowledge-based theory; capacity.

Craft industry; handloom industry; industrial context; industry; information services; information systems; regulation; telecommunications industry; biotech; legal profession; linkages with military and defence systems; private venture-backed firms; public institutions; piracy; hidden hand.

Institutional economics; institutional environment; institutional quality; institutional theory; institutional voids; signalling firm quality; signalling value; signalling; institutional entrepreneurship; Imprinting; social embeddedness.

Parenthood; family; family business success; family business sustainability; family integrity; family ownership and management; founding family leadership; sustainable family business model; subjective family business success; objective family business success

Small and medium sized enterprises; small business; small firms

Consulting firms; non-profit; tourism entrepreneurship; internet; internet-based firms; bricolage. 